\title{
Neonatal Drug Depression and Respiratory Distress Managed by Positive Pressure Ventilation and Exchange Transfusion
}

\author{
J. A. YOUNG and S. RASHEED \\ From Aberdeen Maternity Hospital
}

The use of chlormethiazole in obstetrics to prevent eclampsia is relatively new and in recommended dosage does not result in undue depression of the fetus (Duffus, Tunstall, and MacGillivray, 1968). We describe here the management of a situation which resulted from the use of chlormethiazole in heavy dosage, which had been necessary to achieve anaesthesia for the duration of labour in an unmanageable patient under psychiatric care.

\section{Case Report}

A female infant weighing $2875 \mathrm{~g}$. was delivered by forceps after 39 weeks' gestation. In the 22 hours before delivery, her mother had received $22.4 \mathrm{~g}$. chlormethiazole. In this time, she was also given $100 \mathrm{mg}$. pethidine, $150 \mathrm{mg}$. 'pethilorfan', $25 \mathrm{mg}$. promazine, and $12.5 \mathrm{mg}$. prochlorperazine, but not within 6 hours of delivery.

On delivery the baby was severely asphyxiated, the Apgar scores being 1 at 1 minute and 2 at 5 minutes, and no spontaneous respiratory efforts were observed. Endotracheal intubation was performed at 2 minutes and manual intermittent positive pressure ventilation (IPPV) with $100 \%$ oxygen was given for 2 hours. At this stage only occasional unsustained respiratory efforts were made, and IPPV was continued using the East Radcliffe Respirator, as described by Tunstall et al. (1968). Metabolic acidosis was countered by intravenous sodium bicarbonate and a prophylactic course of ampicillin and cloxacillin was given.

After 9 hours' ventilation, the dead space had to be increased because of diminished $\mathrm{PCO}_{2}$. This, together with the fact that the metabolic acidosis was not increasing, indicated that alveolar ventilation and respiration were adequate.

After ventilation for 23 hours, the nasotracheal tube was accidentally displaced and the opportunity was taken to review the baby's condition.

Spontaneous respiration was sustained for only 10 minutes and there were no spontaneous movements, no response to stimulation, and no muscle tone. These

Received February 12, 1969. findings suggested that there was severe depression of cortical function. Artificial ventilation was continued. Chest $x$-ray taken at this time showed granular mottling and an 'air bronchogram', and was considered to be typical of hyaline membrane disease. The blood gas analyses were within the normal range (see Table).

Because of the continued suppression of cerebral function and because of the large dose of chlormethiazole involved, it was decided to carry out exchange transfusion. Blood samples for chlormethiazole assay were taken before and after the procedure (analyses by Astra, Sweden-chlormethiazole content as base, before-3.1 $\mu \mathrm{g} . / \mathrm{ml}$. , after-2.9 $\mu \mathrm{g} . / \mathrm{ml}$.) which was started when the baby was 34 hours old. During the exchange transfusion, $480 \mathrm{ml}$. blood were exchanged by the continuous method; there was no change in muscle tone, but towards the end there was slight response to skin stimulation by flicking, and spontaneous movements were noted for the first time. There was, however, no major change in the general state.

By 42 hours there were some spontaneous movements, and spontaneous respiratory effort was being sustained, though irregularly. Over the next 24 hours the baby's condition improved steadily, and at the age of 66 hours she was extubated. Thereafter she maintained adequate spontaneous respiration and responded normally to stimuli. During the following few hours the clinical picture of respiratory distress syndrome developed. Respiration was characterized by intercostal and subcostal indrawing, xiphoid retraction, tachypnoea, and an

TABLE

Blood Gas Analyses

\begin{tabular}{r|c|c|c|c|c|c}
\hline $\begin{array}{c}\text { Age } \\
\text { (hr.) }\end{array}$ & $p \mathrm{H}$ & $\begin{array}{c}\mathrm{P}_{\mathrm{a}} \mathrm{CO}_{2} \\
(\mathrm{~mm} . \mathrm{Hg})\end{array}$ & $\begin{array}{c}\text { Standard } \\
\mathrm{Bi}- \\
\text { carbonate } \\
(\mathrm{mEq} / \mathrm{l} .)\end{array}$ & $\begin{array}{c}\text { Actual } \\
\text { Bi- } \\
\text { carbonate } \\
(\mathrm{mEq} / 1 .)\end{array}$ & $\begin{array}{c}\text { Base } \\
\text { Deficit } \\
(\mathrm{mEq} / \mathrm{l} .)\end{array}$ & $\begin{array}{c}\text { Buffer } \\
\text { Base } \\
(\mathrm{mEq} / 1 .)\end{array}$ \\
\hline 2 & $7 \cdot 20$ & 52 & $16 \cdot 5$ & $19 \cdot 5$ & 10 & 42 \\
7 & $7 \cdot 56$ & 19 & $23 \cdot 5$ & 16 & 1 & 52 \\
11 & $7 \cdot 34$ & 44 & $21 \cdot 5$ & 23 & 2 & 49 \\
66 & $7 \cdot 35$ & 52 & $24 \cdot 5$ & 28 & 2 & 55 \\
77 & $7 \cdot 28$ & 110 & 30 & 48 & 10 & 65 \\
90 & $7 \cdot 50$ & 38 & 29 & $28 \cdot 5$ & $8 \cdot 5$ & 61 \\
\hline
\end{tabular}


expiratory moan. Cyanosis was absent in an atmosphere of $60 \%$ oxygen.

Despite conservative management in humid oxygen with intravenous bicarbonate, the $\mathrm{P}_{\mathrm{a}} \mathrm{CO}_{2}$ rose over the next 12 hours to $110 \mathrm{~mm}$. $\mathrm{Hg}$. At this stage IPPV was started again and continued for 15 hours. After the period of IPPV, chest $x$-ray showed an appearance compatible with resolving hyaline membrane disease. Blood gas analysis showed normal values (Table). Further progress was uneventful and the baby was discharged at the age of 3 weeks, weighing $2730 \mathrm{~g}$.

\section{Discussion}

The principal action of chlormethiazole is cortical depression. It has been used in preeclampsia, in epilepsy, and in delirium tremens. It is known that chlormethiazole crosses the placenta (Duffus et al., 1968). More detailed studies in experimental animals have shown that the concentration of the drug in the fetal circulation approximately equals that of the maternal circulation within a few minutes after administration to the mother, and that its excretion is rapid and mainly renal (Allgén, Lindberg, and Ullberg, 1963). It is presumed that in the newborn infant reported here, renal function could not deal with the large dose of the drug, and prolonged depression of cerebral function resulted. With artificial ventilation, recovery would probably have been complete without the aid of exchange transfusion, but this procedure probably shortened the ventilation period by accelerating the elimination of the drug.
It is of interest that, though the radiological appearance characteristic of the respiratory distress syndrome was evident on the first day of life, the complete clinical picture did not develop until the baby had been breathing spontaneously for some hours, at the age of almost 3 days. This suggests that some of these clinical features may depend on exhaustion of the infant's respiratory muscles, and lends support to the treatment of such patients with artificial ventilation.

\section{Summary}

A newborn baby is described in whom cerebral depression resulted from administration of a large dose of chlormethiazole to the mother during labour. IPPV was required for 66 hours, and an exchange transfusion was also given. During the subsequent recovery phase, clinical and radiological features of hyaline membrane disease were observed.

\section{REFERENCES}

Allgén, L. C., Lindberg, U. H., and Ullberg, S. (1963). Tissue distribution, excretion and metabolism of heminevrin, Di4-methyl-5-(-chloraethyl)-thiazolium ethanedisulphonate. (In Swedish.) Nord. psykiat. T., 27, 13.

Duffus, Gillian M., Tunstall, M. E., and MacGillivray, I. (1968). Intravenous chlormethiazole in pre-eclamptic toxaemia in labour. Lancet, 1, 335.

Tunstall, M. E., Cater, J. I., Thomson, Jean S., and Mitchell, R. G. (1968). Ventilating the lungs of newborn infants for prolonged periods. Arch. Dis. Childh., 43, 486.

Correspondence to Dr. J. A. Young, Special Nursery, Maternity Hospital, Aberdeen. 